\title{
Underwater endoscopic resection of an ileal neuroendocrine tumor
}

The small bowel is the third most common site of neuroendocrine tumors (NETs) after the lung and rectum, and NETs represent the most frequent malignancy of the small bowel [1]. Small bowel NETs are usually managed with surgical resection [2]. However, in some situations surgery may be too difficult or not feasible.

Underwater endoscopic resection was initially described for the treatment of colorectal polyps and flat lesions [3], and later for resection of the rectum [4] and duodenum NETs [5] with good results. However, there is no report of underwater endoscopic resection for small bowel NETs. We describe, for the first time, a case of an ileal NET resected with an underwater endoscopic technique ( $\triangleright$ Video 1 ).

A 64-year-old man who had previously undergone a total colectomy with ileorectal anastomosis (> Fig. $\mathbf{1}$ ) was referred for endoscopic treatment of a low-grade NET located at the distal ileum. The endoscopic assessment revealed an elevated, yellowish, 10-mm subepithelial lesion consistent with an NET, located $15 \mathrm{~cm}$ proximal to the ileorectal anastomosis ( Fig.2). Due to the low risk of malignancy and the difficulty involved in a possible surgical approach, the surgical team decided for a less invasive treatment by endoscopic resection.

Under endoscopic visualization, water was infused until the ileum lumen was completely filled. A 13-mm snare and an endocut mode were used for the resection (\$ Fig.3). After resection, endoscopic examination revealed no signs of perforation or residual lesion ( $\mathbf{F i g . 4}$ ). Histologic analysis of the specimen revealed a well-differentiated grade 1 NET invading the superficial submucosal layer with tumor-free, resected deep and lateral margins and without angiolymphatic or perineural invasion.

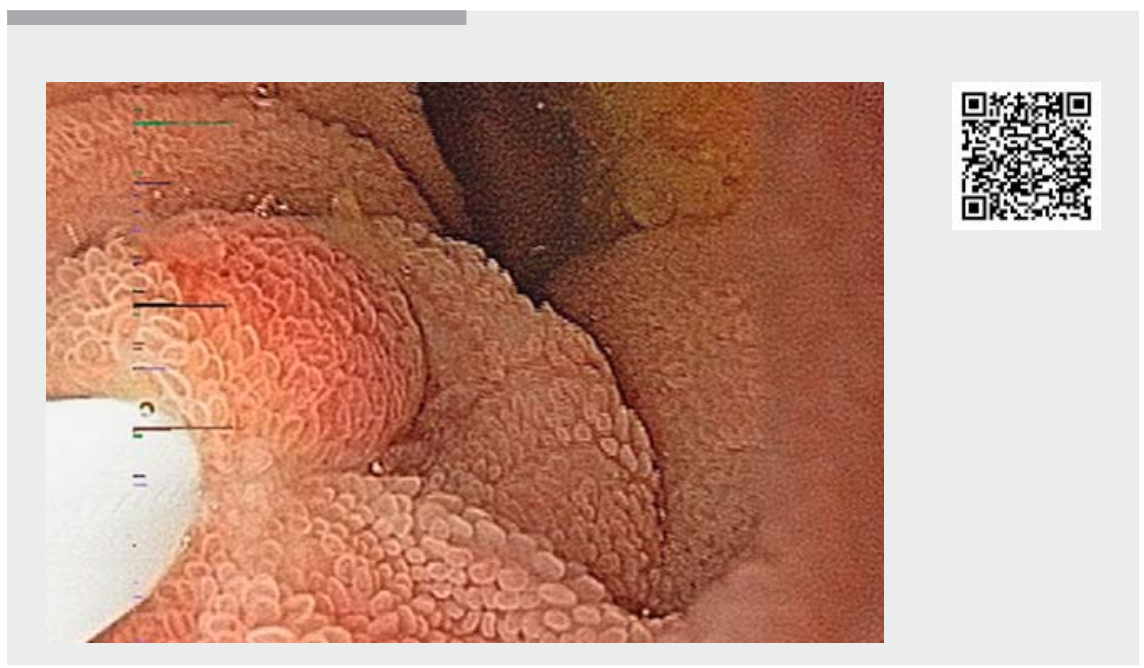

$\checkmark$ Video 1 Underwater endoscopic resection of an ileal neuroendocrine tumor.



- Fig. 1 lleorectal anastomosis of patient referred for endoscopic treatment of neuroendocrine tumor.



Fig. 3 Underwater resection of ileal neuroendocrine tumor with $13 \mathrm{~mm}$ snare.

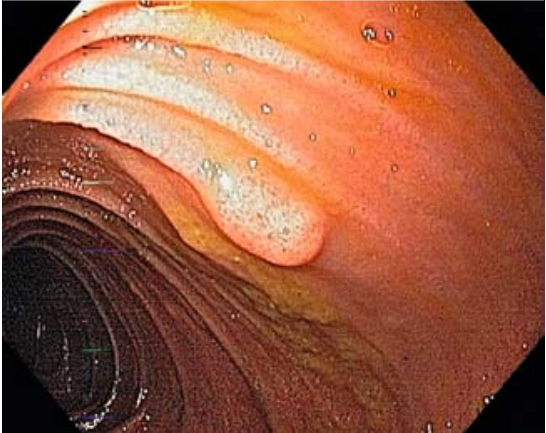

$\checkmark$ Fig. 2 Ileal neuroendocrine tumor located proximal to the ileorectal anastomosis.

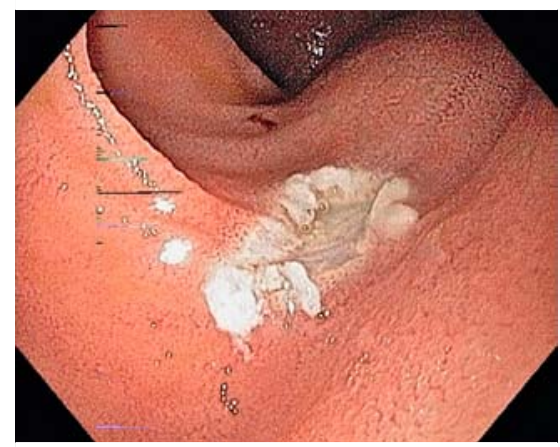

Fig. 4 Endoscopic view after resection of neuroendocrine tumor. 
Underwater endoscopic resection can be a new therapeutic strategy for a lowgrade ileal neuroendocrine tumor and was feasible in this case.

Endoscopy_UCTN_Code_TTT_1AP_2AD

\section{Competing interests}

The authors declare that they have no conflict of interest.

The authors

Daniel T. Rezende ${ }^{1}$, Fábio S. Kawaguti ${ }^{1}$, Adriana V. Safatle-Ribeiro ${ }^{1}$, Luciano H. L. Tolentino ${ }^{1}$, Ulysses Ribeiro Junior ${ }^{2}$, Fauze Maluf-Filho ${ }^{1}$

1 Division of Endoscopy, Cancer Institute of University of São Paulo Medical School, São Paulo, Brazil

2 Division of Surgery, Cancer Institute of University of São Paulo Medical School, São Paulo, Brazil
Corresponding author

Fábio S. Kawaguti

Instituto do Cancer do Estado de São Paulo, Divisão de Endoscopia - $2^{\circ}$ andar, Av. Dr. Arnaldo 251, São Paulo/SP, 01246-000, Brazil

Fax: +55-11-3069-757

shiguehiss@yahoo.com.br

\section{References}

[1] Bilimoria KY, Bentrem DJ, Wayne JD et al. Small bowel cancer in the United States: changes in epidemiology, treatment, and survival over the last 20 years. Ann Surg 2009; 249: 63-71

[2] Niederle B, Pape UF, Costa F et al. ENETS Consensus Guidelines Update for Neuroendocrine Neoplasms of the Jejunum and lleum. Neuroendocrinology 2016; 103 : 125-138

[3] Binmoeller KF, Weilert F, Shah J et al. "Underwater" EMR without submucosal injection for large sessile colorectal polyps (with video). Gastrointes Endosc 2012; 75: 10861091

[4] Kawaguti FS, de Oliveira JF, da Costa Martins $B$ et al. Underwater endoscopic resection of a neuroendocrine rectal tumor. Endoscopy 2015; 47: 513-514

[5] Anderloni A, Murino A, Jovani M et al. Underwater endoscopic mucosal resection of a duodenal neuroendocrine tumor. Gastrointest Endosc 2016; 83: 259-260
Bibliography

Endoscopy 2021; 53: E48-E49

DOI 10.1055/a-1178-0143

ISSN 0013-726X

published online 5.6.2020

(c) 2020. Thieme. All rights reserved.

Georg Thieme Verlag KG, Rüdigerstraße 14 ,

70469 Stuttgart, Germany

\section{ENDOSCOPY E-VIDEOS}

https:/|eref.thieme.de/e-videos

回回 Endoscopy E-Videos is a free

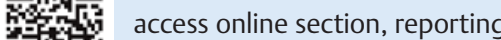
回被 on interesting cases and new

techniques in gastroenterological endoscopy. All papers include a high quality video and all contributions are freely accessible online.

This section has its own submission website at https://mc.manuscriptcentral.com/e-videos 